\title{
Feasibility of Clinical Application of Ultrasound Molecular Imaging
}

\author{
Kentaro Otani \\ Department of Regenerative Medicine and Tissue Engineering \\ National Cerebral and Cardiovascular Center Research Institute
}

Japan

\section{Introduction}

Ultrasound imaging has been utilized for the non-invasive and real-time observation of pathophysiological conditions in clinical settings. To enhance blood flow signals, microbubbles that are quite different in acoustic impedance from blood have been utilized as the contrast agent for ultrasound imaging. Unfortunately, the initial performance of intravenous contrast-enhanced ultrasound imaging was hampered by the pulmonary circulation due to the size of the microbubbles. Additionally, the detection of microbubbles was not easy because of the weak signals derived from the bubbles. However, recent improvements in the bubble physics and ultrasound imaging technologies have enabled non-invasive assessment of organ perfusion by intravenous administration of microbubbles (Chahal \& Senior, 2010; Porter \& Xie, 2010; Wilson \& Burns, 2010). Of note, the fate of intravenously administrated microbubbles is similar to that of red blood cells (Keller et al., 1989; Jayaweera et al., 1994). Many contrast agents for contrast-enhanced ultrasound imaging are now clinically available all over the world (Table 1).

On the other hand, ultrasound molecular imaging, which visualizes molecular dynamics in situ by detecting the signals derived from retained microbubbles in the target regions, has been recently developed. As microbubbles are the intravascular blood flow tracer, ultrasound molecular imaging predominantly targets activated leukocytes and molecules expressed on endothelial cells. Many papers have been published regarding the diagnostic utility of ultrasound molecular imaging for the detection of inflammation, atherosclerosis and tumor angiogenesis (Villanueva \& Wagner, 2008; Leong-Poi, 2009; Lindner, 2009; Chadderdon \& Kaul, 2010; Deshpande et al., 2010).

The utility of molecular imaging has been demonstrated using several modalities, including positron emission tomography (PET), magnetic resonance imaging (MRI) and near-infrared fluorescence (NIRF) (Jaffer \& Weissleder, 2005). Although PET and MRI provide accurate diagnostic information, the versatility of these two modalities is limited. On the other hand, ultrasound examination is cost effective and is able to be performed at the bedside. Therefore, the adaptation of ultrasound molecular imaging for clinical settings is desired.

For the clinical translation of ultrasound molecular imaging, however, some bottlenecks need to be overcome at the same time, including the development of clinically translatable targeted bubbles and the improvement of ultrasound imaging techniques. This chapter summarizes the recent advances in the preparation of targeted bubbles and ultrasound 
imaging technologies for realizing the clinical translation of ultrasound molecular imaging in the near future.

\begin{tabular}{cccc} 
& Core gas & Shell composition & Mean diameter \\
\hline \hline $\begin{array}{c}\text { Levovist } \\
\text { Bayer Yakuhin, Ltd. } \\
\text { Osaka, Japan }\end{array}$ & Air & Palmitic acid & $2.0-3.0 \mu \mathrm{m}$ \\
\hline $\begin{array}{c}\text { Optison } \\
\text { GE Healthcare } \\
\text { Buckinghamshire, } \mathrm{UK}\end{array}$ & $\mathrm{C}_{3} \mathrm{~F}_{8}$ & Human serum albumin & $3.0-4.5 \mu \mathrm{m}$ \\
\hline $\begin{array}{c}\text { Definity } \\
\text { Lantheus Medical Imaging, Inc. } \\
\text { N. Billerica, MA }\end{array}$ & $\mathrm{C}_{3} \mathrm{~F}_{8}$ & Phospholipid & $1.1-3.3 \mu \mathrm{m}$ \\
\hline $\begin{array}{c}\text { Sonovue } \\
\text { Bracco Imaging SpA } \\
\text { Milan, Italy }\end{array}$ & $\mathrm{SF}_{6}$ & Phospholipid & $2.5 \mu \mathrm{m}$ \\
\hline $\begin{array}{c}\text { Sonazoid } \\
\text { Daiichi-Sankyo Co., Ltd. } \\
\text { Tokyo, Japan }\end{array}$ & $\mathrm{C}_{4} \mathrm{~F}_{10}$ & $\begin{array}{c}\text { Hydrogenated egg } \\
\text { phosphatidylserine }\end{array}$ & $2.0-3.0 \mu \mathrm{m}$ \\
\hline
\end{tabular}

Table 1. Commercially available ultrasound contrast agents

\section{Recent progress in development of targeted bubbles}

In the previously reported animal studies with ultrasound molecular imaging, various intravital molecules have served as target molecules (Chadderdon \& Kaul, 2010; Hwang et al., 2010). In ultrasound molecular imaging, the methodology for accumulating bubbles at a specific target is a principal issue. Until now, two types of bubbles have been developed to achieve this purpose, including non-targeted and targeted bubbles (Dayton \& Rychak, 2007; Deshpande et al., 2010) (Table 2).

\begin{tabular}{ccc} 
& Method to modify bubbles & Application \\
\hline \hline Non-targeted bubbles & $\begin{array}{c}\text { Incorporate phospholipids/lipids } \\
\text { into bubble shell by sonication }\end{array}$ & $\begin{array}{c}\text { Inflammation imaging, } \\
\text { Kupffer imaging }\end{array}$ \\
\hline Targeted bubbles & $\begin{array}{c}\text { Attach ligands onto bubble surface } \\
\text { via covalent/non-covalent coupling }\end{array}$ & Overall \\
\hline
\end{tabular}

Table 2. Two types of bubbles for ultrasound molecular imaging

Non-targeted bubbles contain phosphatidylserine (PS) or other lipids in their shell components, and have been utilized as the contrast agent for inflammation and Kupffer cell 
imaging (Lindner et al., 2000; Christiansen et al., 2002; Watanabe et al., 2007; Yanagisawa et al., 2007). On the other hand, targeted bubbles bear antibodies or peptides on the surface of the shell via chemical conjugation, including covalent or non-covalent coupling methods (Hernot \& Klibanov, 2008; Deshpande et al., 2010). Several kinds of potential covalent coupling reaction have been considered for the attachment of ligands onto the surface of bubbles (Klibanov, 2005; Kiessling et al., 2009) (Table 3). However, the major method for ligand attachment in recent ultrasound molecular imaging studies was non-covalent avidinbiotin complex formation because of its versatility.

\section{Primary coupling reaction}

\section{Carboxylic Acid (-COOH) / Amine (-NH$)$}

\section{Covalent coupling}

Maleimide / Thiol (-SH)

Aldehyde (-CHO) / Amine (-NH$)$ etc.

Non-covalent coupling

Biotin / Avidin or Streptavidin

\section{Table 3. Coupling strategies for attachment of ligands onto bubble shell}

It is well known that the binding between biotin and streptavidin exhibits extremely high affinity (dissociation constant $\sim 0^{-15}$ ); however, at the same time, streptavidin is a major barrier for clinical translation of targeted bubbles. Because of the immunogenicity of streptavidin, repeated injection of streptavidin-containing bubbles is difficult in humans (Marshall et al., 1996; Carter, 2001). Therefore, the development of targeted bubbles that do not contain streptavidin is necessary for the clinical translation of ultrasound molecular imaging.

\subsection{Commercially available targeted bubbles for basic research}

Because of its difficulty, the preparation of targeted bubbles has been a principal issue in ultrasound molecular imaging. Fortunately, several targeted bubbles only for use in basic research have been developed recently; MicroMarker ${ }^{\circledR}$ (VisualSonics Inc., Toronto, Canada) and Targestar TM /Visistar ${ }^{\mathrm{TM}}$ (Targeson Inc., San Diego, CA, USA). Because of their versatility, these bubbles have been well utilized in in vivo studies (Rychak et al., 2007; Willmann et al., 2008a, 2008b, 2010; Barreiro et al., 2009). However, the clinical application of these bubbles is difficult in the present condition because of the use of streptavidin as a mediator between bubbles and ligands.

\subsection{Chemical modification to improve targetability of bubbles}

For ultrasound molecular imaging, improvement of the targetability of ligand-bearing bubbles to the disease-related intravital molecule is a principal issue. To this end, several chemical modifications have been recently applied to targeted bubbles (Klibanov, 2009; Gessner \& Dayton, 2010). Firstly, Klibanov et al. conjugated clustered polymeric forms of ligands onto the surface of the bubble shell to increase the surface density of ligands 
(Klibanov et al., 2006b). Secondly, targeted bubbles for two intravital molecules have been developed by simultaneous conjugation of two kinds of ligands onto the bubble shell (Weller et al., 2005; Willmann et al., 2008b; Ferrante et al., 2009). However, dense ligands, especially antibodies on the bubble surface would increase the risk of non-specific binding and immunogenic responses at the same time. To overcome this issue, Borden et al. developed "stealth bubbles" those ligands were buried in a forest of long polyethylene glycol (PEG)-brushes (Borden et al., 2008). In this stealth bubble, a radiation force was required to induce emergence and activation of the buried ligands. Therefore, the utilization of buried ligands might enable the development of targeted bubbles with both low nonspecific binding and low immunogenic response.

\subsection{Streptavidin-free targeted ultrasound contrast agents}

Recently, several approaches for the preparation of targeted bubbles without streptavidin have been demonstrated. Anderson et al. utilized covalent maleimide-thiol coupling for conjugating the targeting ligands onto the bubble shell (Anderson et al., 2010). As well as avidin-biotin binding, this covalent coupling approach would be applicable to a wide variety of ligands in the near future. Meanwhile, novel vascular endothelial growth factor 2 (VEGFR2)-specific bubbles; BR55, which contains a lipopeptide construct in the bubble shell, was recently developed (Pysz et al., 2010; Pochon et al., 2010; Tardy et al., 2010). Since BR55 contains neither antibodies nor biotin/streptavidin complex, the clinical translation of targeted bubbles for angiogenesis without an immunogenic response might be feasible by using BR55.

\subsection{Preparation of targeted bubbles based on clinically available bubbles}

To achieve easy translation of ultrasound molecular imaging in clinical settings, we considered that the easiest approach would be the preparation of targeted bubbles based on a clinically available ultrasound contrast agent. However, there have been no reports regarding the preparation of targeted bubbles based on a clinically available contrast agent. Sonazoid, a clinically available ultrasound contrast agent in Japan, consists of perfluorobutane gas microbubbles stabilized by a membrane of hydrogenated egg PS (Sontum, 2008). Generally, PS is well known as an important molecule in the cellular apoptotic process, especially in the clearance of apoptotic cells (Wu et al., 2006; Nagata et al., 2010). Under normal physiological conditions, PS is sequestered from the cell surface by phospholipid translocators, known as flippases. However, this process is interrupted during apoptosis and PS translocates to the cell surface. This translocation of PS triggers the recognition and removal of apoptotic cells by phagocytes. In the field of apoptotic research, annexin $\mathrm{V}$ has been well utilized for detecting PS-expressing apoptotic cells (Vermes et al., 1995). Recently, the clinical availability of annexin $\mathrm{V}$ for the detection of apoptosis or plaque instability was demonstrated (Hofstra et al., 2000; Narula et al., 2001; Kietselaer et al., 2004).

In ultrasound molecular imaging, PS-containing bubbles have been utilized as targeted bubbles for activated leukocytes (Lindner et al., 2000; Christiansen et al., 2002). Interestingly, PS-containing bubbles were labeled with annexin V as well as apoptotic cells (Lindner et al., 2000). Based on this result, we hypothesized that preparation of antibody-carrying bubbles based on Sonazoid could be feasible by detecting PS in Sonazoid with annexin V and utilizing avidin-biotin complex formation (Figure 1). 


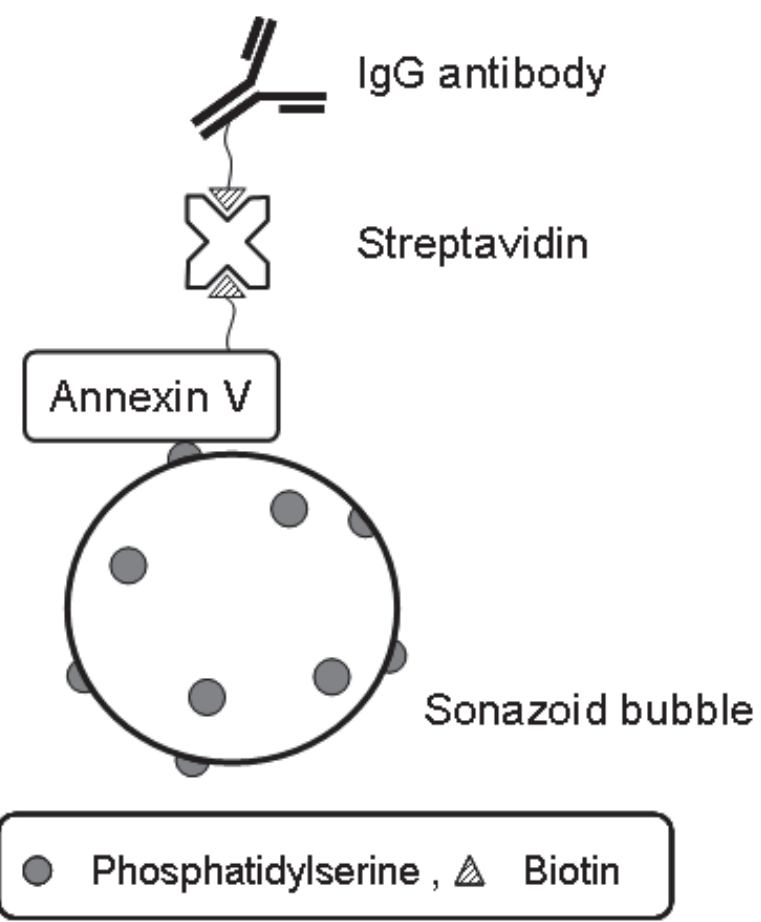

Fig. 1. Theoretical schema of IgG antibody-carrying bubbles based on Sonazoid through use of annexin $\mathrm{V}$ and avidin-biotin complex formation.

As annexin V is a well-known protein that detects PS in a $\mathrm{Ca}^{2+}$-dependent manner, we firstly examined the effect of $\mathrm{Ca}^{2+}$ addition on Sonazoid bubbles. By adding a higher concentration of $\mathrm{CaCl}_{2}$, obvious and significant aggregation of bubbles was observed (Figure 2A). The size distribution histogram was markedly smaller after the addition of $0.25 \mathrm{mmol} / \mathrm{L} \mathrm{CaCl}_{2}$ than that of naked Sonazoid bubbles (Figure 2B). Additionally, the bubble concentration was markedly reduced after the addition of $0.25 \mathrm{mmol} / \mathrm{L} \mathrm{CaCl}_{2}$ (naked Sonazoid: $5.3 \times 10^{8}$ bubbles/mL vs. $0.25 \mathrm{mmol} / \mathrm{L} \mathrm{CaCl}_{2}: 7.0 \times 10^{7}$ bubbles $/ \mathrm{mL}$ ). This phenomenon was considered to result from neutralization of the surface charge of Sonazoid bubbles (Otani \& Yamahara, 2011). However, bubble number was not decreased after the addition of 0.05 $\mathrm{mmol} / \mathrm{L} \mathrm{CaCl}_{2}\left(5.8 \times 10^{8}\right.$ bubbles/mL) (Figure 2B). Therefore, the following experiments were performed in the presence of $0.05 \mathrm{mmol} / \mathrm{L} \mathrm{CaCl}_{2}$, which did not induce obvious aggregation of Sonazoid bubbles.

Secondly, the attachment of annexin V to the PS in Sonazoid bubbles was examined using fluorescein isothiocianate (FITC)-conjugated annexin V. The fluorescent signal was determined by FACSCalibur (BD Bioscience, San Jose, CA, USA). Even in the condition with low $\mathrm{Ca}^{2+}$, FITC-positive bubbles were observed after the conjugation of Sonazoid bubbles with FITC-annexin V (Figure 3). In contrast, the fluorescent signal derived from bubbles after conjugation in the absence of $\mathrm{Ca}^{2+}$ was significantly reduced. These results imply that the PS in Sonazoid could be detected by using annexin V even in the condition of 0.05 $\mathrm{mmol} / \mathrm{L} \mathrm{CaCl}_{2}$ (Otani \& Yamahara, 2011). 
A.

$\mathrm{CaCl}_{2}(\mathrm{mmol} / \mathrm{L})$

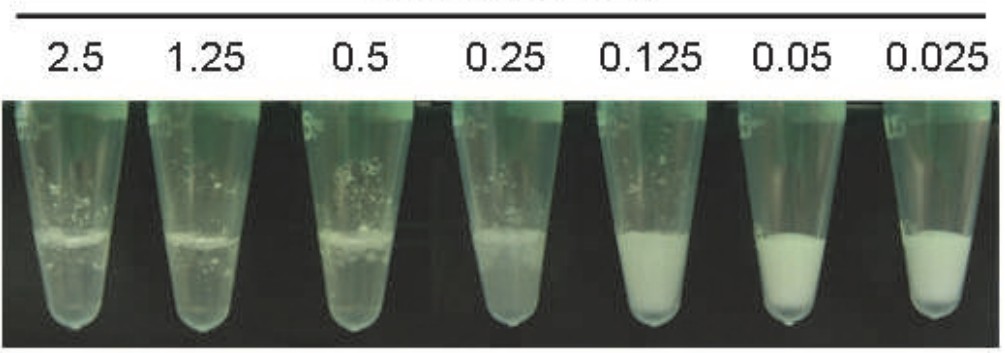

B.

Sonazoid bubbles

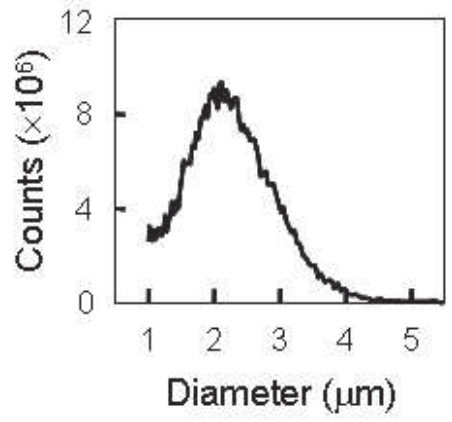

Sonazoid bubbles

$0.25 \mathrm{mmol} / \mathrm{L} \mathrm{CaCl}$

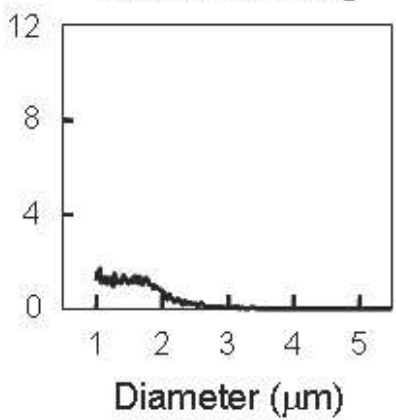

Sonazoid bubbles

$0.05 \mathrm{mmol} / \mathrm{L} \mathrm{CaCl}$

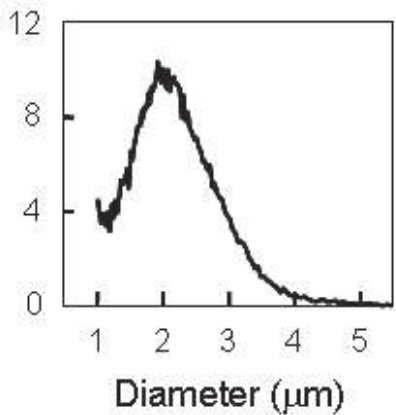

Fig. 2. Changes of Sonazoid bubbles after addition of $\mathrm{CaCl}_{2}$. A) At 30 minutes after addition of $\mathrm{CaCl}_{2}$, obvious bubble aggregation was observed when the concentration of $\mathrm{CaCl}_{2}$ was $0.25 \mathrm{mmol} / \mathrm{L}$ or higher. B) The size distribution of Sonazoid bubbles was markedly altered at 45 minutes after $0.25 \mathrm{mmol} / \mathrm{L} \mathrm{CaCl}_{2}$ addition. (Reproduced from Otani et al. with permission)

Thirdly, we examined whether streptavidin could detect biotinylated-Sonazoid bubbles with annexin V. Sonazoid bubbles were conjugated with biotinylated-annexin V followed by R-phycoerythrin (PE)-conjugated streptavidin. A strong PE signal was detected from Sonazoid bubbles in the presence of biotinylated-annexin V (Figure 4). However, the PE signal was obviously weaker in the absence of biotinylated-annexin V. These results imply that streptavidn could attach to the surface of Sonazoid via avidin-biotin binding.

Finally, we examined whether the attachment of IgG antibodies onto the surface of Sonazoid bubbles is feasible via annexin $\mathrm{V}$ and avidin-biotin complex formation. Sonazoid bubbles were conjugated with biotinylated-annexin $\mathrm{V}$ followed by streptavidin and biotinylatedAlexa488-IgG. As shown in Figure 5A, Alexa488-positive bubbles were confirmed by FACS analysis (Otani \& Yamahara, 2011). However, the suspension of targeted-Sonazoid bubbles was obviously thinner than that of naked Sonazoid bubbles (Figure 5B). 

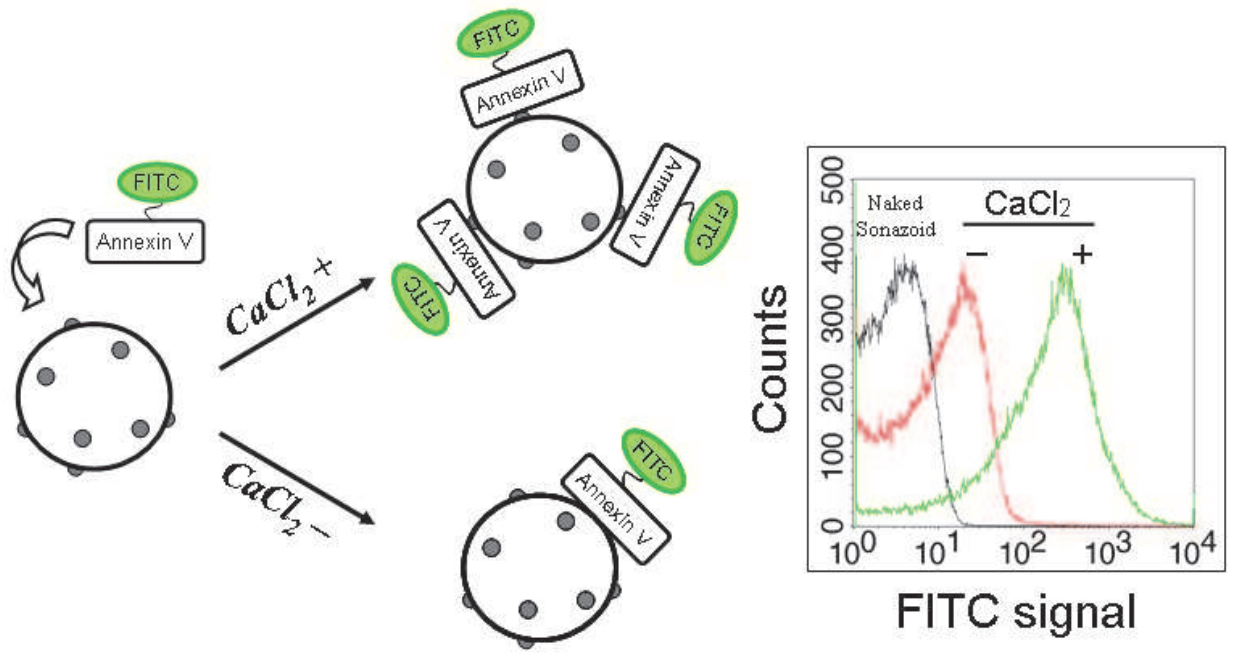

Fig. 3. Attachment of annexin V to PS on surface of Sonazoid bubble. In the presence of $\mathrm{CaCl}_{2}$, FITC-positive bubbles were detected after the conjugation of Sonazoid bubbles with FITC-annexin V. In contrast, the FITC signal derived from Sonazoid bubbles was markedly reduced in the absence of $\mathrm{CaCl}_{2}$. (Reproduced from Otani et al. with permission)
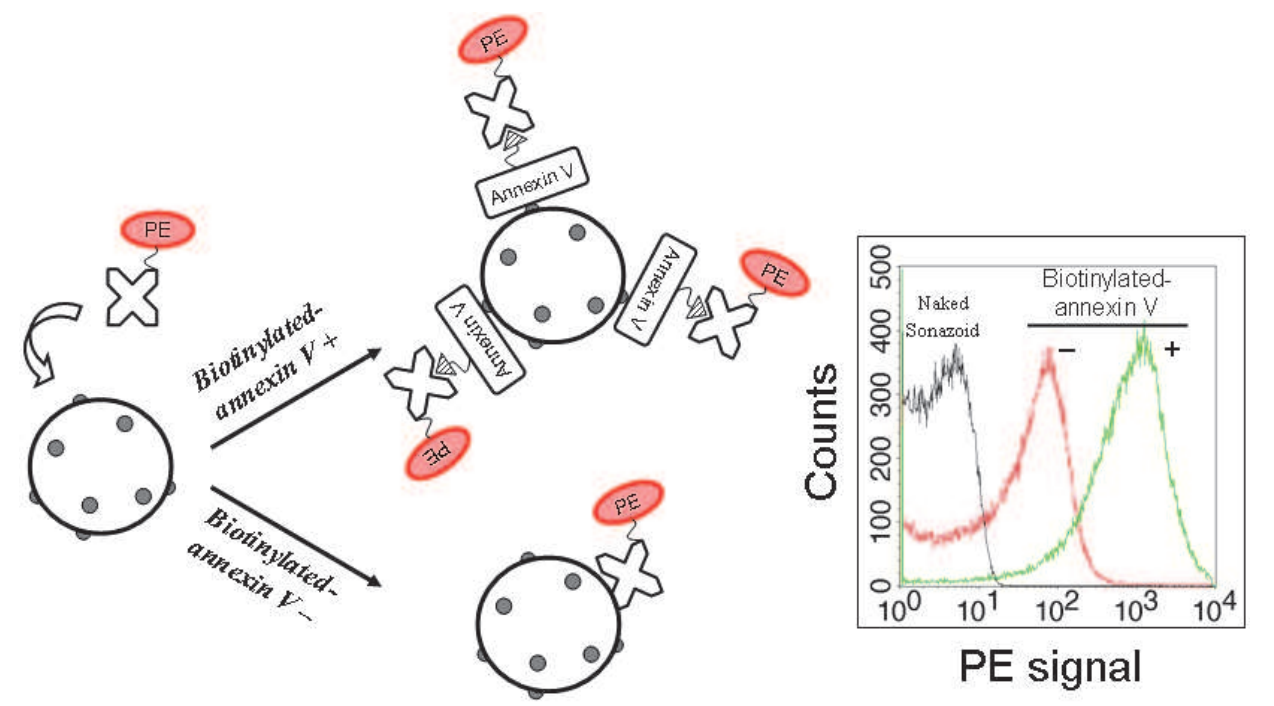

Fig. 4. Attachment of streptavidin to surface of Sonazoid bubble via avidin-biotin binding. PE-positive bubbles were detected after conjugation of Sonazoid bubbles with biotinylatedannexin V followed by PE-conjugated streptavidin. However, the PE signal was markedly reduced in the absence of biotinylated-annexin V. (Reproduced from Otani et al. with permission) 


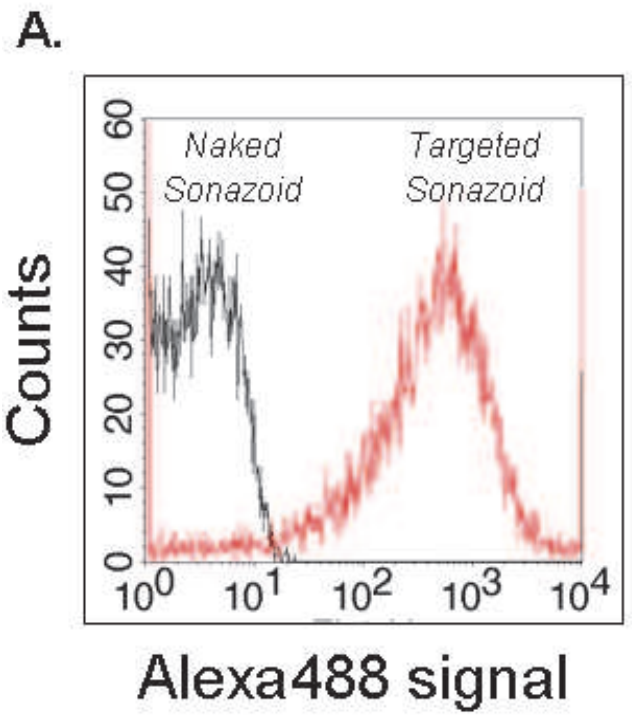

B.

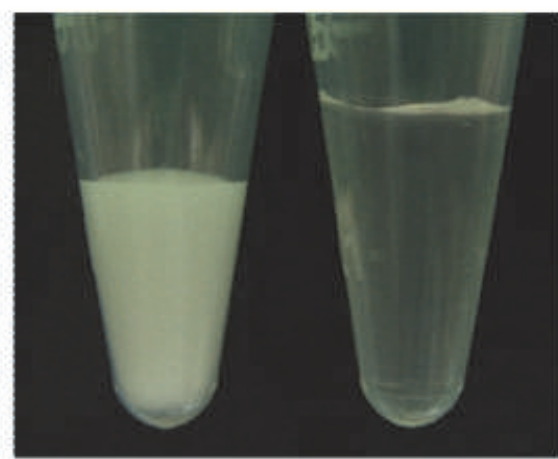

Naked Targeted Sonazoid Sonazoid

Fig. 5. IgG-carrying bubbles based on Sonazoid. A) Alexa488-positive Sonazoid bubbles were confirmed after conjugation with biotinylated-annexin $\mathrm{V}$ followed by streptavidin and biotinylated-Alexa488-IgG. B) The concentration of targeted bubbles based on Sonazoid was obviously lower than that of naked Sonazoid bubbles. (Reproduced from Otani et al. with permission)

Although our preliminary results demonstrated the feasibility of preparation of targeted bubbles based on clinically available microbubbles Sonazoid, the translation of targeted Sonazoid bubbles to in vivo settings would be difficult in the present circumstances because of the decrease of bubble number and the use of streptavidin. However, our results imply that PS in Sonazoid bubbles has the potential to be a mediator of targeted bubbles based on Sonazoid.

\subsection{Improvement of targeted sonazoid by using lactadherin}

PS is well known as an important molecule for the clearance of apoptotic cells, and several kinds of proteins that bind with PS have been discovered (Wu et al., 2006; Nagata et al., 2010). Milk fat globule epithelial growth factor 8 (MFG-E8)/lactadherin is a glycoprotein which was originally identified as a component of milk fat globules (Stubbs et al., 1990). Lactadherin contains a PS-binding C-domain and an RGD (arginine-glycine-aspartate)-motif present in the epidermal growth factor domain, which binds to integrins av $\beta 3$ and $\operatorname{av} \beta 5$ (Andersen et al., 2000; Hanayama et al., 2002; Yamaguchi et al., 2008). It is well known that the recognition of PS by lactadherin is $\mathrm{Ca}^{2+}$-independent (Shi et al., 2003; Dasgupta et al., 2006). Therefore, we examined whether PS in Sonazoid could be detected using PEconjugated lactadherin instead of annexin V (Figure 6A). By conjugating Sonazoid bubbles with PE-labeled lactadherin, PE-positive bubbles were detected by FACS analysis (Figure 6B, unpublished data). 


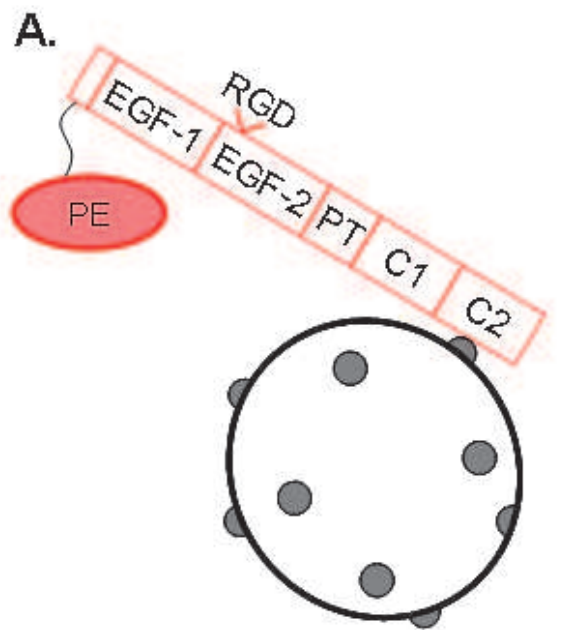

Sonazoid bubble

B.

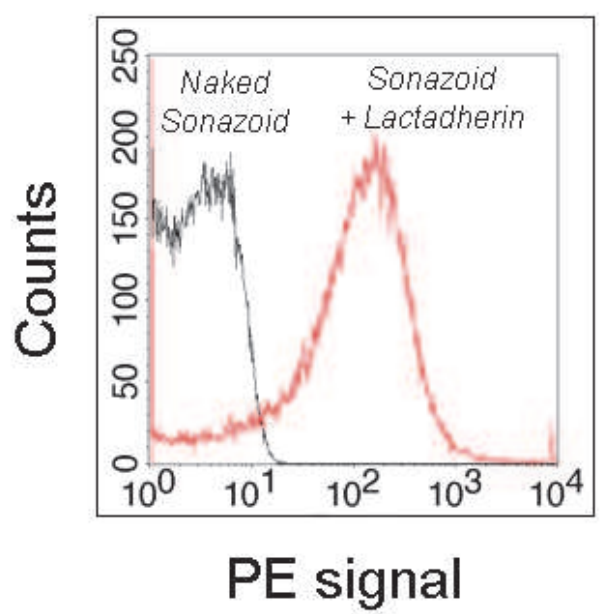

\section{Phosphatidylserine}

Fig. 6. Detection of PS in Sonazoid using lactadherin. A) Schema of expected binding between Sonazoid bubbles and PE-conjugated lactadherin. B) After conjugation with PElactadherin, the presence of PE-positive Sonazoid bubbles was confirmed.

Because of the unnecessity of $\mathrm{Ca}^{2+}$ addition in the case of lactadherin, no obvious aggregation or decrease in number of bubbles was observed during the preparation of lactadherin-bearing bubbles (data not shown). Although the binding between Sonazoid bubbles and annexin V was fragile, robust binding with PS in Sonazoid was achieved using lactadherin (Figure 7). These results imply that lactadherin is superior to annexin $\mathrm{V}$ in regard to the detection of PS in Sonazoid bubbles. As lactadherin has a RGD motif in its epidermal growth factor domain, lactadherin-bearing Sonazoid bubbles might have the potential to attach to integrin av $\beta 3$-expressing cells. Furthermore, lactadherin-bearing Sonazoid bubbles might be a novel targeted bubble for angiogenesis, because the integrin av $\beta 3$ is well known to play a key role in angiogenesis (Friedlander et al., 1995). Therefore, further study to examine the potential of lactadherin-bearing Sonazoid bubbles both in vitro and in vivo would be of benefit.

Although the feasibility of preparation of targeted bubbles based on a clinically available ultrasound contrast agent was demonstrated in our present study, there are some concerns with lactadherin-bearing Sonazoid bubbles at the present time. The most important issue is the direct conjugation of lactadherin onto the bubble shell. This might influence: 1) the efficiency of attachment to the target molecule (integrin av $\beta 3$ ) both in vitro and in vivo studies, and 2) the surface density of ligands. The majority of recent targeted bubbles contain long PEG spacer arms on the bubble surface to project ligands away from the surface of the bubble shell (Klibanov, 2006a; Lindner, 2010). This projection of ligands resulted in improvement of flexibility and targetability of bubbles. Furthermore, the surface density of ligands would be lower in the case of direct conjugation of ligands to the bubble 
shell. In these regards, the efficiency of attachment of lactadherin-bearing Sonazoid bubbles to integrin av $\beta 3$-expressing cells might be low. This concern should be clarified by further study.
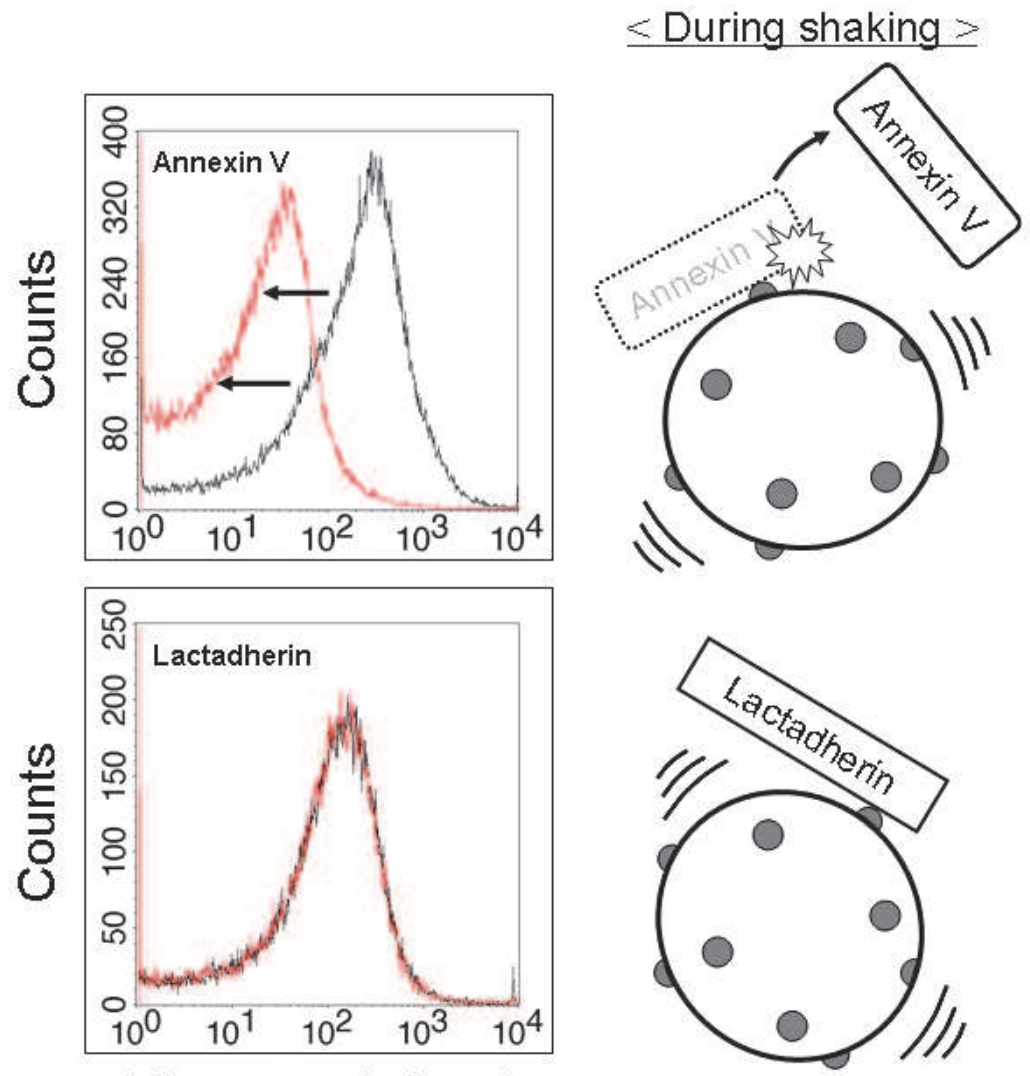

Fluorescent signal

\section{-:Before shaking -:After shaking}

Fig. 7. Stability of annexin V-and lactadherin-bearing Sonazoid bubbles. Compared to annexin V-bearing Sonazoid bubbles, lactadherin-conjugated bubbles were more resistant to violent shaking. (Reproduced from Otani et al. with permission)

\section{Improvement of ultrasound technology}

In conjunction with the development of targeted bubbles, improvement of ultrasound technology is also an essential issue in ultrasound molecular imaging. Unlike conventional contrast-enhanced ultrasound imaging, the number of retained bubbles to the target region is quite small. Therefore, a more sensitive ultrasound detection technique would be required for the clinical translation of ultrasound molecular imaging. Additionally, a bubble-specific 
imaging method that suppresses signals from surrounding tissues, to emphasize the ultrasound signals derived from bubbles, would be a help for accurate observation of molecular dynamics.

\subsection{Evolution of ultrasound detection techniques}

Contrast-enhanced ultrasound imaging visualizes the signals derived from microbubbles. Under high mechanical index (MI) ultrasound exposure, bubbles exhibit unique scattering behavior. By utilizing this characteristic, harmonic imaging, especially second harmonic imaging, has been developed at an early stage of contrast-enhanced ultrasound imaging (Porter et al., 1996). In addition, the Doppler technique has been applied for sensitive detection of bubbles (harmonic power Doppler imaging). Until now, several harmonic imaging techniques including subharmonic, 1.5 harmonic and ultraharmonic imaging have been developed (Table 4). However, high MI ultrasound exposure resulted in the destruction of bubbles - the source of acoustic signals. Therefore, intermittent exposure is inevitable for acquiring contrast-enhanced images in high MI imaging. As a result, real-time observation of contrast enhancement has not been achieved in high MI imaging. To overcome this issue, real-time imaging which utilizes low power ultrasound has been developed in conjunction with high MI imaging techniques. Until now, several techniques that detect the bubble signal efficiently with multiple ultrasound pulses have been developed, including pulse inversion, power pulse inversion, power modulation, coherent contrast imaging and cadence pulse sequencing (Table 4).

\begin{tabular}{|c|c|c|}
\hline & Imaging mode & References \\
\hline \multirow{4}{*}{$\begin{array}{l}\text { High MI imaging techniques } \\
\text { (for intermittent observation) }\end{array}$} & Subharmonic imaging & Forsberg et al., 2000 \\
\hline & 1.5 harmonic imaging & Toshida et al., 2005 \\
\hline & Ultraharmonic imaging & Kuersten et al., 2001 \\
\hline & Harmonic power Doppler & Heinle et al., 2000 \\
\hline \multirow{5}{*}{$\begin{array}{l}\text { Low MI imaging techniques } \\
\text { (for real-time observation) }\end{array}$} & Pulse inversion & Burns et al., 2000 \\
\hline & Power pulse inversion & Tiemann et al., 1999 \\
\hline & Power modulation & Caiani et al., 2005 \\
\hline & Coherent contrast imaging & Otani et al., 2004 \\
\hline & Cadence pulse sequencing & Phillips, 2001 \\
\hline
\end{tabular}

Table 4. Imaging technologies for contrast-enhanced ultrasound imaging 
Compared to conventional contrast-enhanced ultrasound imaging, the number of retained or attached bubbles to the target region in ultrasound molecular imaging is quite small. Additionally, the sensitivity for bubble detection in high MI imaging is higher than that in low MI real-time imaging. Therefore, early examination of ultrasound molecular imaging had been performed using high MI, intermittent imaging (Lindner et al., 2001; Leong-Poi et al., 2003). However, high MI imaging interferes with the continuous imaging of molecular dynamics, due to the destruction of retained or attached bubbles. Recently, low MI, realtime imaging has been applied in ultrasound molecular imaging (Kaufmann et al., 2007; Stieger et al., 2008). Although the acoustic signal derived from targeted bubbles in low MI real-time imaging was weaker than that in high MI imaging, real-time ultrasound molecular imaging would enable temporal and spatial recognition of molecular dynamics (Kaufmann et al., 2010). Additionally, Klibanov et al. reported the feasibility of individual bubble detection using low MI ultrasound imaging (Klibanov et al., 2004). This result implied that the sensitivity of low MI ultrasound techniques would be sufficient for application to ultrasound molecular imaging.

\subsection{Specialized ultrasound machine for small animal research}

In previous small animal studies on ultrasound perfusion and molecular imaging, the detection of bubbles has been performed using clinically available ultrasound imaging systems (Weller et al., 2003; Otani et al., 2008). Recently, high resolution ultrasound imaging systems specialized for small animal experiments have been developed (Vevo770 and Vevo2100; VisualSonics Inc., Toronto, Canada). Several recent basic research studies on ultrasound molecular imaging have utilized these machines (Rychak et al., 2007; Willmann et al., 2008a, 2008b, 2010). Because of the usage of too high frequency ultrasound (center frequency; $55 \mathrm{MHz}$ ), this machine would not be suitable for clinical use. However, the accumulated results from genetically-modified animal studies using these instruments will be of much help for the clinical translation of ultrasound molecular imaging.

\section{Conclusion and future direction}

Contrast-enhanced ultrasound imaging has been applied in clinical settings, and its usability has also been demonstrated all over the world. On the other hand, the utility of ultrasound molecular imaging has been proved by many animal studies. Therefore, the development of clinically translatable targeted bubbles has potential for spreading ultrasound molecular imaging into clinical settings rapidly. In parallel with perfusion or molecular imaging, the potential of microbubbles as a carrier for drug or gene delivery into cells has been demonstrated recently in both in vitro and in vivo studies (Liu et al., 2006; Otani et al., 2009; Tinkov et al., 2009). The combination of these features might lead to the localized delivery of drugs or genes into target cells in vivo. Although further study is required, progress in targeted bubbles physics and ultrasound imaging technologies might realize the clinical application of ultrasound molecular imaging and the development of non-invasive localized drug/gene delivery systems in the near future.

\section{Acknowledgement}

This work was supported by a Grant-in-Aid for Young Scientists (B) from the Ministry of Education, Culture, Sports, Science and Technology (MEXT). 


\section{References}

Andersen, MH., Graversen, H., Fedosov, SN., Petersen, TE., \& Rasmussen, JT. (2000). Functional analysis of two cellular binding domains of bovine lactadherin. Biochemistry, 39, pp. 6200-6206, ISSN 0006-2960.

Anderson, CR., Rychak, JJ., Backer, M., Backer, J., Ley, K., \& Klibanov, AL. (2011). scVEGF microbubble ultrasound contrast agents: a novel probe for ultrasound molecular imaging of tumor angiogenesis. Invest Radiol, 45, pp. 579-585, ISSN 0020-9996.

Barreiro, O., Aguilar, RJ., Tejera, E., Megías, D., de Torres-Alba, F., Evangelista, A., \& Sánchez-Madrid, F. (2009). Specific targeting of human inflamed endothelium and in situ vascular tissue transfection by the use of ultrasound contrast agents. J Am Coll Cardiol Img, 2, pp. 997-1005, ISSN 1936-878X.

Borden, MA., Zhang, H., Gillies, RJ., Dayton, PA., \& Ferrara, KW. (2008). A stimulusresponsive contrast agent for ultrasound molecular imaging. Biomaterials, 29, pp. 597-606, ISSN 0142-9612.

Burns, PN., Wilson, SR., \& Simpson, DH. (2000). Pulse inversion imaging of liver blood flow: improved method for characterizing focal masses with microbubble contrast. Invest Radiol, 35, pp. 58-71, ISSN 0020-9996.

Caiani, EG., Lang, RM., DeCara, J., Bednarz, JE., Weinert, L., Korcarz, CE., Collins, KA., \& Mor-Avi, V. (2005). Objective assessment of left ventricular wall motion from contrast-enhanced power modulation images. J Am Soc Echocardiogr, 15, pp. 118128, ISSN 0894-7317.

Carter, P. (2001). Improving the efficacy of antibody-based cancer therapies. Nat Rev Cancer, 1, pp. 118-129, ISSN 1474-175X.

Chadderdon, SM., \& Kaul, S. (2010). Molecular imaging with contrast enhanced ultrasound. J Nucl Cardiol, 17, pp. 667-677, ISSN 1071-3581.

Chahal, NS., \& Senior, R. (2010). Clinical applications of left ventricular opacification. J Am Coll Cardiol Img, 3, pp. 188-196, ISSN 1936-878X.

Cristiansen, JP., Leong-Poi, H., Klibanov, AL., Kaul, S., \& Lindner, JR. (2002). Noninvasive imaging of myocardial reperfusion injury using leukocyte-targeted contrast echocardiography. Circulation, 105, pp. 1764-1767, ISSN 0009-7322.

Dasgupta, SK., Guchhait, P., \& Thiagarajan, P. (2006). Lactadherin binding and phosphatidylserine expression on cell surface-comparison with annexin A5. Transl Res, 148, pp. 19-25, ISSN 1931-5244.

Dayton, PA., \& Rychak, JJ. (2007). Molecular ultrasound imaging using microbubble contrast agents. Front Biosci, 12, pp. 5124-5142. ISSN 1093-9946.

Deshpande, N., Pysz, MA., \& Willmann, JK. (2010). Molecular ultrasound assessment of tumor angiogenesis. Angiogenesis, 13, pp. 175-188, ISSN 0969-6970.

Ferrante, EA., Pickard, JE., Rychak, J., Klibanov, A., \& Ley, K. (2009). Dual targeting improves microbubble contrast agent adhesion to VCAM-1 and P-selectin under flow. J Control Release, 140, pp. 100-107, ISSN 0168-3659.

Forsberg, F., Shi, WT., \& Goldberg, BB. (2000). Subharmonic imaging of contrast agents. Ultrasonics, 38, pp. 93-98, ISSN 0041-624X.

Friedlander, M., Brooks, PC., Shaffer, RW., Kincaid, CM., Varner, JA., \& Cheresh, DA. (1995) Definition of two angiogenic pathways by distinct alpha v integrins. Science, 270, pp. 1500-1502, ISSN 0036-8075. 
Gessner, R., \& Dayton, PA. (2010). Advances in molecular imaging with ultrasound. Mol Imaging, 9, pp. 117-127, ISSN 1535-3508.

Hanayama, R., Tanaka, M., Miwa, K., Shinohara, A., Iwamatsu, A., \& Nagata, S. (2002). Identification of a factor links apoptotic cells to phagocytes. Nature, 417, pp. 182187, ISSN 0028-0836.

Heinle, SK., Noblin, J., Goree-Best, P., Mello, A., Ravad, G., Mull, S., Mammen, P., \& Grayburn, PA. (2000). Assessment of myocardial perfusion by harmonic power Doppler imaging at rest and during adenosine stress: comparison with 99mTcsestamibi SPECT imaging. Circulation, 102, pp. 55-60, ISSN 0009-7322.

Hernot, S., \& Klibanov, AL. (2008). Microbubbles in ultrasound-triggered drug gene delivery. Adv Drug Deliv Rev, 60, pp. 1153-1166, ISSN 0169-409X.

Hofstra, L., Liem, IH., Dumont, EA., Boersma, HH., van Heerde, WL., Doevendans, PA., DeMuinck, E., Wellens, HJ., Kemerink, GJ., Reutelingsperger, CP., \& Heidendal, GA. (2000). Visualisation of cell death in vivo in patients with acute myocardial infarction. Lancet, 356, pp. 209-212, ISSN 0140-6736.

Hwang, M., Lyshchik, A., \& Fleischer, AC. (2010). Molecular sonography with targeted microbubbles: current investigations and potential applications. Ultrasound $Q, 26$, pp. 75-82, ISSN 0894-8771.

Jaffer, FA., \& Weissleder, R. (2005). Molecular imaging in the clinical arena. JAMA, 293, pp. 855-862, ISSN 0098-7484.

Jayaweera, AR., Edwards, N., Glasheen, WP., Villanueva, FS., Abbott, RD., \& Kaul, S. (1994). In vivo myocardial kinetics of air-filled albumin microbubbles during myocardial contrast echocardiography: comparison with radiolabeled red blood cells. Circ Res, 74, pp. 1157-1165, ISSN 0009-7300.

Kaufmann, BA., Sanders, JM., Davis, C., Xie, A., Aldred, P., Sarembock, IJ., \& Lindner, JR. (2007). Molecular imaging of inflammation in atherosclerosis with targeted ultrasound detection of vascular cell adhesion molecule-1. Circulation, 116, pp. 276284, ISSN 0009-7322

Kaufmann, BA., Carr, CL., Belcik, T., Xie, A., Kron, B., Yue, Q., \& Lindner, JR. (2010). Effect of acoustic power on in vivo molecular imaging with targeted microbubbles: implication for low-mechanical index real-time imaging. J Am Soc Echocardiogr, 23, pp. 79-85, ISSN 0894-7317.

Keller, MW., Segal, SS., Kaul, S., \& Duling, B. (1989). The behavior of sonicated albumin microbubbles within the microcirculation: a basis for their use during myocardial contrast echocardiography. Circ Res, 65, pp. 458-467, ISSN 0009-7300.

Kiessling, F., Huppert, J., \& Palmowski, M. (2009). Functional and molecular ultrasound imaging: concepts and contrast agents. Curr Med Chem, 16, pp. 627-642, ISSN 09298673.

Kietselaer, BL., Reutelingsperger, CP., Heidendal, GA., Daemen, MJ., Mess, WH., Hofstra, L., \& Narula, J. (2004). Noninvasive detection of plaque instability with use of radiolabeled annexin A5 in patients with carotid-artery atherosclerosis. $N$ Engl J Med, 350, pp. 1472-1473, ISSN 0028-4793.

Klibanov, AL., Rasche, PT., Hughes, MS., Wojdyla, JK., Galen, KP., Wible, JH., \& Brandenburger, GH. (2004). Detection of individual microbubbles of ultrasound contrast agents: imaging of free-floating and targeted bubbles. Invest Radiol, 39, pp. 187-195, ISSN 0020-9996. 
Klibanov, AL. (2005). Ligand-carrying gas-filled microbubbles: ultrasound contrast agents for targeted molecular imaging. Bioconjugate Chem, 16, pp. 9-17, ISSN 1043-1802.

Klibanov, AL. (2006). Microbubble contrast agents: targeted ultrasound imaging and ultrasound assisted drug-delivery application. Invest Radiol, 41, pp. 354-362, ISSN 0020-9996.

Klibanov, AL., Rychak, JJ., Yang, WC., Alikhani, S., Acton, S., Lindner, JR., Ley, K., \& Kaul, S. (2006). Targeted ultrasound contrast agent for molecular imaging of inflammation in high-shear flow. Contrast Media Mol Imaging, 1, pp. 259-266, ISSN 1555-4309.

Klibanov, AL. (2009). Preparation of targeted microbubbles: ultrasound contrast agents for molecular imaging. Med Biol Eng Comput, 47, pp. 875-882, ISSN 0140-0118.

Kuersten, B., Murthy, TH., Li, P., Liu, Z., Locricchio, E., Baisch, C., Rafter, P., \& Vannan, M. (2001). Ultraharmonic myocardial contrast imaging: in vivo experimental and clinical data from a novel technique. J Am Soc Echocardiogr, 14, pp. 910-916, ISSN 0894-7317.

Leong-Poi, H., Christiansen, J., Klibanov, AL., Kaul, S., \& Lindner, JR. (2003). Noninvasive assessment of angiogenesis by ultrasound and microbubbles targeted to $\mathrm{a}_{\mathrm{v}^{-}}$ integrins. Circulation, 107, pp. 455-460, ISSN 0009-7322.

Leong-Poi, H. (2009). Molecular imaging using contrast-enhanced ultrasound: evaluation of angiogenesis and cell therapy. Cardiovasc Res, 84, pp. 190-200, ISSN 0008-6363.

Lindner, JR., Song, J., Xu. F., Klibanov, AL., Singbartl, K., Ley, K., \& Kaul, S. (2000). Noninvasive ultrasound imaging of inflammation using microbubbles targeted to activated leukocytes. Circulation, 102, pp. 2745-2750, ISSN 0009-7322.

Lindner, JR., Song, J., Christiansen, J., Klibanov, AL., Xu, F., \& Ley, K. (2001). Ultrasound assessment of inflammation and renal tissue injury with microbubbles targeted to P-selectin. Circulation, 104, pp. 2107-2112, ISSN 0009-7322.

Lindner, JR. (2009). Contrast ultrasound molecular imaging of inflammation in cardiovascular disease. Cardiovasc Res, 84, pp. 182-189, ISSN 0008-6363.

Lindner, JR. (2010). Molecular imaging of vascular phenotype in cardiovascular disease: new diagnostic opportunities on the horizon. J Am Soc Echocardiogr, 23, pp. 343-350, ISSN 0894-7317.

Liu, Y., Miyoshi, H., \& Nakamura, M. (2006). Encapsulated ultrasound microbubbles: therapeutic application in drug/gene delivery. J Control Release, 114, pp. 89-99, ISSN 0168-3659.

Marshall, D., Pedley, RB., Boden, JA., Boden, R., Melton, RG., \& Begent, RHJ. (1996). Polyethylene glycol modification of a galactosylated streptavidin clearing agent: effects on immunogenicity and clearance of a biotinylated anti-tumour antibody. $\mathrm{Br}$ J Cancer, 73, pp. 565-572, ISSN 0007-0920.

Nagata, S., Hanayama, R., \& Kawane, K. (2010). Autoimmunity and the clearance of dead cells. Cell, 140, pp. 619-630, ISSN 0092-8674.

Narula, J., Acio, ER., Narula, N., Samuels, LE., Fyfe, B., Wood, D., Fitzpatrick, JM., Raghunath, PN., Tomaszewski, JE., Kelly, C., Steinmetz, N., Green, A., Tait, JF., Leppo, J., Blankenberg, FG., Jain, D., \& Strauss, HW. (2001). Annexin-V imaging for noninvasive detection of cardiac allograft rejection. Nat Med, 7, pp. 1347-1352, ISSN 1078-8956. 
Otani, K., Toshida, T., Iwata, A., Asanuma, T., Ishikura, F., \& Beppu, S. (2004). Adenosine triphosphate stress myocardial contrast echocardiography detects coronary artery stenosis with greater sensitivity than wall-motion abnormality measurements. J Am Soc Echocardiogr, 17, pp. 1275-1280, ISSN 0894-7317.

Otani, K., Ohnishi, S., Obata, H., Ishida, O., Kitamura, S., \& Nagaya, N. (2008). Contrast sonography enables noninvasive and quantitative assessment of neovascularization after stem cell transplantation. Ultrasound Med Biol, 34, pp. 1893-1900, ISSN 03015629.

Otani, K., Yamahara, K., Ohnishi, S., Obata, H., Kitamura, S., \& Nagaya, N. (2009). Nonviral delivery of siRNA into mesenchymal stem cells by a combination of ultrasound and microbubbles. J Control Release, 133, pp. 146-153, ISSN 0168-3659.

Otani, K., \& Yamahara, K. (2011). Development of antibody-carrying microbubbles based on clinically available ultrasound contrast agent for targeted molecular imaging: a preliminary chemical study. Mol Imaging Biol, 13, pp. 250-256, ISSN 1536-1632.

Phillips, PJ. (2001). Contrast pulse sequences (CPS): imaging nonlinear microbubbles. Proceedings of the Institute of Electrical and Electronics Engineers (IEEE) Ultrasonics Symposium, 2, pp. 1739-1745, ISSN 1051-0117.

Pysz, MA., Foygel, K., Rosenberg, J., Gambhir, SS., Schneider, M., \& Willmann, JK. (2010). Antiangiogenic cancer therapy: monitoring with molecular US and a clinically translatable contrast agent (BR55). Radiology, 256, pp. 519-527, ISSN 0033-8419.

Pochon, S., Tardy, I., Bussat, P., Bettinger, T., Brochot, J., von Wronski, M., Passantino, L., \& Schneider, M. (2010). BR55: a lipopeptide-based VEGFR2-targeted ultrasound contrast agent for molecular imaging of angiogenesis. Invest Radiol, 45, pp. 89-95, ISSN 0020-9996.

Porter, TR., Xie, F., Kricsfeld, D., \& Armbruster, RW. (1996). Improved myocardial contrast with second harmonic transient ultrasound response imaging in humans using intravenous perfluorocarbon-exposed sonicated dextrose albumin. I Am Coll Cardiol, 27, pp. 1497-1501, ISSN 0735-1097.

Porter, TR., \& Xie, F. (2010). Myocardial perfusion imaging with contrast ultrasound. J Am Coll Cardiol Img, 3, pp. 176-187, ISSN 1936-878X.

Rychak, JJ., Graba, J., Cheung, AM., Mystry, BS., Lindner, JR., Kerbel, RS., \& Foster, FS. (2007). Microultrasound molecular imaging of vascular endothelial growth factor receptor 2 in a mouse model of tumor angiogenesis. Mol Imaging, 6, pp. 289-296, ISSN 1535-3508.

Shi, J., \& Gilbert, GE. (2003). Lactadherin inhibits enzyme complexes of blood coagulation by competing for phospholipid-binding sites. Blood, 101, pp. 2628-2636, ISSN 00064971.

Sontum, PC. (2008). Physicochemical characteristics of Sonazoid, a new contrast agent for ultrasound imaging. Ultrasound Med Biol, 34, pp. 824-833, ISSN 0301-5629.

Stieger, SM., Dayton, PA., Borden, MA., Caskey, CF., Griffey, SM., Wisner, ER., \& Ferrara, KW. (2008). Imaging of angiogenesis using Cadence ${ }^{\mathrm{TM}}$ contrast pulse sequencing and targeted contrast agents. Contrast Media Mol Imaging, 3, pp. 9-18, ISSN 15554309.

Stubbs, JD., Lekutis, C., Singer, KL., Bui, A., Yuzuki, D., Srinivasan, U., \& Parry, G. (1990). cDNA cloning of a mouse mammary epithelial cell surface protein reveals the 
existence of epidermal growth factor-like domains linked to factor VIII-like sequences. Proc Natl Acad Sci USA, 87, pp. 8417-8421, ISSN 0027-8424.

Tardy, I., Pochon, S., Theraulaz, M., Emmel, P., Passantino, L., Tranquart, F., \& Schneider, M. (2010) Ultrasound molecular imaging of VEGFR2 in a rat prostate tumor model using BR55. Invest Radiol, 45, pp. 573-578, ISSN 0020-9996.

Tiemann, K., Lohmeier, S., Kuntz, S., Köster, J., Pohl, C., Burns, P., Porter, TR., Nanda, NC., Lüderitz, B., \& Becher, H. (1999). Real-time contrast echo assessment of myocardial perfusion at low emission power: first experimental and clinical results using power pulse inversion imaging. Echocardiography, 16, pp. 799-809, ISSN 0742-2822.

Tinkov, S., Bekeredjian, R., Winter, G., \& Coester, C. (2009). Microbubbles as ultrasound triggered drug carries. J Pharm Sci, 98, pp. 1935-1961, ISSN 0022-3549.

Toshida, T., Ishikura, F., Asanuma, T., Iwata, A., Miki, A., Otani, K., \& Beppu, S. (2005). Efficacy of 1.5 harmonic imaging for intravenous myocardial contrast echocardiography. J Echocardiogr, 3, pp. 104-108, ISSN 1349-0222.

Vermes, I., Haanen, C., Steffen-Nakken, H., \& Reutelingsperger, H. (1995). A novel assay for apoptosis. Flow cytometric detection of phosphatidylserine expression on early apoptotic cells using fluorecein labeled annexin V. J Immunol Methods, 184, pp. 3951, ISSN 0022-1759.

Villanueva, FS., \& Wagner, WR. (2008). Ultrasound molecular imaging of cardiovascular disease. Nat Clin Pract Cardiovasc Med, 5, pp. S26-32, ISSN 1743-4297.

Watanabe, R., Matsumura, M., Munemasa, T., Fujimaki, M., \& Suematsu, M. (2007). Mechanism of hepatic parenchyma-specific contrast of microbubble-based contrast agent for ultrasonography: microscopic studies in rat liver. Invest Radiol, 42, pp. 643-651, ISSN 0020-9996.

Weller, GER., Lu, E, Csikari, MM, Klibanov, AL., Fischer, D., Wagner, WR., \& Villanueva, FS. (2003). Ultrasound imaging of acute cardiac transplant rejection with microbubbles targeted to intercellular adhesion molecule-1. Circulation, 108, pp. 218-224, ISSN 0009-7322.

Weller, GER., Villanueva, FS., Tom, EM., \& Wagner, WR. (2005). Targeted ultrasound contrast agents: in vitro assessment of endothelial dysfunction and multi-targeting to ICAM-1 and Sialyl Lewisx. Biotechnol Bioeng, 92, pp. 780-788, ISSN 0006-3592.

Willmann, JK., Paulmurugan, R., Chen, K., Gheysens, O., Rodriguez-Porcel, M., Lutz, AM., Chen, IY., Chen, X., \& Gambhir, SS. (2008). US imaging of tumor angiogenesis with microbubbles targeted to vascular endothelial growth factor receptor type 2 in mice. Radiology, 246, pp. 508-518, ISSN 0033-8419.

Willmann, JK., Lutz, AM., Paulmurugan, R., Patel, MR., Chu, P., Rosenberg, J., \& Gambhir, SS. (2008). Dual-targeted contrast agent for US assessment of tumor angiogenesis in vivo. Radiology, 248, pp. 936-944, ISSN 0033-8419.

Willmann, JK., Kimura, RH., Deshpande, N., Lutz, AM., Cochran, JR., \& Gambhir, SS. (2010). Targeted contrast-enhanced ultrasound imaging of tumor angiogenesis with contrast microbubbles conjugated to integrin-binding knottin peptides. J Nucl Med, 51, pp. 433-440, ISSN 0161-5505.

Wilson, SR., \& Burns, PN. (2010). Microbubble-enhanced US in body imaging: what role? Radiology, 257, pp. 24-39, ISSN 0033-8419.

Wu, Y., Tibrewal, N., \& Birge, RB. (2006). Phosphatidylserine recognition by phagocytes: a view to a kill. Trends Cell Biol, 16, pp. 189-197, ISSN 0962-8924. 
Yamaguchi, H., Takagi, J., Miyamae, T., Yokota, S., Fujimoto, T., Nakamura, S., Ohshima, S., Naka, T., \& Nagata, S. (2008). Milk fat globule EGF factor 8 in the serum of human patients of systemic lupus erythematosus. J Leukoc Biol, 83, pp. 1300-1307, ISSN 0741-5400.

Yanagisawa, K., Moriyasu, F., Miyahara, T., Yuki, M., \& Iijima, H. (2007). Phagocytosis of ultrasound contrast agent microbubbles by Kupffer cells. Ultrasound Med Biol, 33, pp. 318-325, ISSN 0301-5629. 


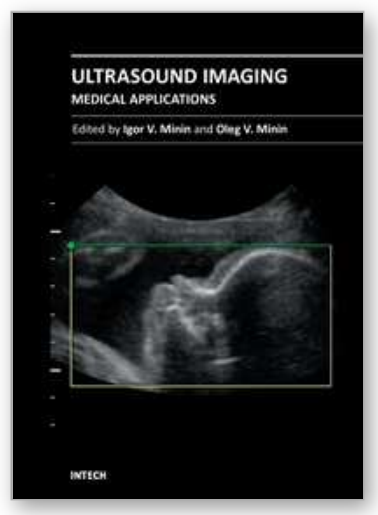

\author{
Ultrasound Imaging - Medical Applications \\ Edited by Prof. Oleg Minin
}

ISBN 978-953-307-279-1

Hard cover, 330 pages

Publisher InTech

Published online 23, August, 2011

Published in print edition August, 2011

This book provides an overview of ultrafast ultrasound imaging, 3D high-quality ultrasonic imaging, correction of phase aberrations in medical ultrasound images, etc. Several interesting medical and clinical applications areas are also discussed in the book, like the use of three dimensional ultrasound imaging in evaluation of Ashermanâ $€^{\mathrm{TM} S}$ syndrome, the role of $3 \mathrm{D}$ ultrasound in assessment of endometrial receptivity and follicular vascularity to predict the quality oocyte, ultrasound imaging in vascular diseases and the fetal palate, clinical application of ultrasound molecular imaging, Doppler abdominal ultrasound in small animals and so on.

\title{
How to reference
}

In order to correctly reference this scholarly work, feel free to copy and paste the following:

Kentaro Otani (2011). Feasibility of Clinical Application of Ultrasound Molecular Imaging, Ultrasound Imaging Medical Applications, Prof. Oleg Minin (Ed.), ISBN: 978-953-307-279-1, InTech, Available from:

http://www.intechopen.com/books/ultrasound-imaging-medical-applications/feasibility-of-clinical-application-ofultrasound-molecular-imaging

\section{INTECH}

open science | open minds

\section{InTech Europe}

University Campus STeP Ri

Slavka Krautzeka 83/A

51000 Rijeka, Croatia

Phone: +385 (51) 770447

Fax: +385 (51) 686166

www.intechopen.com

\section{InTech China}

Unit 405, Office Block, Hotel Equatorial Shanghai

No.65, Yan An Road (West), Shanghai, 200040, China

中国上海市延安西路65号上海国际贵都大饭店办公楼 405 单元

Phone: +86-21-62489820

Fax: +86-21-62489821 
(C) 2011 The Author(s). Licensee IntechOpen. This chapter is distributed under the terms of the Creative Commons Attribution-NonCommercialShareAlike-3.0 License, which permits use, distribution and reproduction for non-commercial purposes, provided the original is properly cited and derivative works building on this content are distributed under the same license. 